\title{
Síndrome de Guillain-Barré associada à COVID-19: uma revisão sistemática
}

\author{
Guillain-Barré syndrome associated with COVID-19: a systematic review \\ Síndrome de Guillain-Barré asociado con COVID-19: una revisión sistemática
}

Recebido: 31/10/2021 | Revisado: 09/11/2021 | Aceito: 15/11/2021 | Publicado: 24/11/2021

\author{
Maria Eduarda de Azeredo Amaral \\ ORCID: https://orcid.org/0000-0002-9413-4661 \\ Universidade de Rio Verde, Brasil \\ E-mail: mariaeduardadeazeredo@hotmail.com.br \\ Lucilla Ribeiro Ávila \\ ORCID: https://orcid.org/0000-0001-7634-2371 \\ Centro Universitário de Goiatuba, Brasil \\ E-mail: lucillaavila@unicerrado.edu.br \\ Bernardo Merrighi de Figueiredo Amaral \\ ORCID: https://orcid.org/0000-0002-7485-3765 \\ Faculdade Ciências Médicas de Minas Gerais, Brasil \\ E-mail: bernardomerrighi@gmail.com \\ Arthur Kalil Santana Nasser \\ ORCID: https://orcid.org/0000-0002-8649-3007 \\ Faculdade Ciências Médicas de Minas Gerais, Brasil \\ E-mail: arthurnasser7@gmail.com \\ João Pedro Martins e Silva \\ ORCID: https://orcid.org/0000-0002-5437-9250 \\ Universidade de Rio Verde, Brasil \\ E-mail: martinsjoaopedro460@gmail.com \\ José Hítallo Anchieta Taveira \\ ORCID: https://orcid.org/0000-0001-8889-7067 \\ Universidade de Rio Verde, Brasil \\ E-mail: hitalotaveira@gmail.com
}

\begin{abstract}
Resumo
O SARS-CoV-2 é um vírus pertencente à família dos coronavírus, e agente causador da COVID-19. Foi descoberto no ano de 2019, na cidade de Wuhan, China, teve disseminação mundial, gerando uma série de incertezas com relação à sua imunopatologia e consequências em um curto prazo de tempo. Dentre os estudos analisados, parece existir uma possível relação de infecção prévia da COVID-19 e desenvolvimento da Síndrome de Guillain-Barré (SGB), uma polirradiculoneuropatia imune aguda. $O$ presente estudo com protocolo registrado na Open Science (https://osf.io/qe625) visa analisar a literatura publicada a respeito do mecanismo com o qual a COVID-19 pode desencadear a SGB como quadro secundário. Para isso, utilizou-se a metodologia de revisão sistemática, com coleta de dados realizada do dia 16 de março de 2021 até o dia 28 de março de 2021, utilizando estratégias de buscas individuais descritas de acordo com anexo 1 nas bases de dados da PubMed e Embase. Os critérios de inclusão foram: artigos que descrevessem o mecanismo da SGB após infecção de por SARS-CoV-2 confirmada, excluindo-se revisões sistemáticas, narrativas, de literatura ou metanálises, assim como não foram aceitos relatos com pacientes pediátricos, hebiátricos, obstétricos e geriátricos. Os resultados apresentaram 11 artigos descrevendo os mecanismos, sendo que 2 foram estudos de coorte e 9 relatos de caso, todos de pacientes infectados e com COVID-19 manifestando secundariamente SGB. Conclui-se que, apesar da literatura escassa, o SARS-CoV-2 pode desencadear respostas imunoinflamatórias que desencadeiam um quadro de complicação neurológica de SGB.
\end{abstract}

Palavras-chave: Infecções por Coronavírus; SARS-CoV-2; Síndrome de Guillain-Barré.

\begin{abstract}
SARS-CoV-2 is a virus belonging to the coronavirus family and the causative agent of COVID-19. It was discovered in 2019 in Wuhan City, China, it had worldwide dissemination, generating a series of uncertainties regarding its immunopathology and consequences in a short period of time. Among the studies analyzed, there seems to be a possible relationship of previous COVID-19 infection and development of Guillain-Barré Syndrome (GBS), an acute immune polyradiculoneuropathy. The present study with a protocol registered in Open Science (https://osf.io/qe625) aims to analyze the published literature of the mechanism with which COVID-19 can trigger GBS as a secondary framework. To this do so, the methodology of systematic review was used, with data collection performed from March 16, 2021 to March 28, 2021, using individual search strategies described according to Annex 1 in pubmed and embase databases. Inclusion criteria were: articles describing the mechanism of GBS after confirmed SARS-CoV-2 infection, excluding systematic reviews, narrative reviews, literature reviews or meta-analyses, as well as reports with pediatric, hebiatric,
\end{abstract}


obstetric and geriatric patients were not accepted. The results showed 11 articles describing the mechanisms, of which 2 were cohort studies and 9 case reports, all from infected patients with COVID-19 secondarily manifesting GBS. It is concluded that, despite the sparse literature, SARS-CoV-2 can trigger immunoinflammatory responses that trigger a neurological complication picture of GBS.

Keywords: Coronavirus Infections; SARS-CoV-2; Guillain-Barre Syndrome.

\section{Resumen}

El SARS-CoV-2 es un virus perteneciente a la familia de los coronavirus y agente causante del COVID-19. Descubierta en el año 2019 en la ciudad de Wuhan, China, tuvo una difusión mundial, generando una serie de incertidumbres respecto a su inmunopatología y consecuencias en un corto periodo de tiempo. Entre los estudios revisados, parece existir una posible relación de la infección previa de COVID-19 y el desarrollo del Síndrome de Guillain-Barré (SGB), una polirradiculoneuropatía inmunológica aguda. El presente estudio con protocolo registrado en el Open Science (https://osf.io/qe625) tiene como objetivo analizar la literatura publicada respecto al mecanismo por el cual el COVID19 puede desencadenar el SGB como condición secundaria. Para ello, se utilizó la metodología de revisión sistemática, con la recogida de datos realizada desde el 16 de marzo de 2021 hasta el 28 de marzo de 2021, utilizando estrategias de búsqueda individuales descritas según el anexo 1 en las bases de datos PubMed y Embase. Los criterios de inclusión fueron: artículos que describieran el mecanismo del SGB tras una infección confirmada por SARS-CoV-2, excluyendo las revisiones sistemáticas, las revisiones narrativas, las revisiones bibliográficas o los meta-análisis, así como los informes con pacientes pediátricos, hebiáticos, obstétricos y geriátricos. Los resultados mostraron 11 artículos que describían los mecanismos, de los cuales 2 eran estudios de cohortes y 9 informes de casos, todos de pacientes infectados y con COVID-19 que manifestaban secundariamente el SGB. Se concluye que, a pesar de la escasa literatura, el SARS$\mathrm{CoV}-2$ puede desencadenar respuestas inmunoinflamatorias que desencadenan un cuadro de complicación neurológica del SGB.

Palabras clave: Infecciones por Coronavirus; SARS-CoV-2; Síndrome de Guillain-Barré.

\section{Introdução}

A síndrome de Guillain Barré (SGB) é a principal, mais comum e mais grave doença neurológica causadora de paralisia em seres humanos (Willisson et al.; 2016). Sabe-se que a SGB é uma condição patológica onde o sistema imunológico danifica os nervos (FRANK, et al.; 2020), resultando em diversos danos na vida da pessoa acometida, entre eles a diminuição da força, fadiga, dor e até mesmo a incapacidade física do indivíduo (Creange et al.; 2016). O intervalo de tempo dos primeiros sintomas até o diagnóstico da SGB varia entre 1 a 150 dias, com mediana de 7 dias e média de 15 dias. Com relação à sua etiologia, tem sido descrito até o momento que esta síndrome é desencadeada por qualquer outra forma de estimulação do sistema imune, como vacinas ou infecções antecedentes. Estes quadros infecciosos podem ser ocasionados tanto por infecções bacterianas quanto virais, como em casos dos agentes infecciosos Campylobacter jejuni e Zika vírus, respectivamente (Willisson et al.; 2016).

Recentemente, com a pandemia mundial da COVID-19 (do inglês: Coronavirus Disease 2019), cujo agente infeccioso é o SARS-CoV-2, foi sugerida uma possível relação entre a infecção por esse vírus e o desencadeamento da SGB (Yachou et al.; 2020). Em um estudo realizado por Frank et al. (2020), foi demonstrado que um paciente de 15 anos desenvolveu a SGB em decorrência da infecção por SARS-CoV-2. Sendo assim, é de grande importância a investigação dessa correlação, uma vez que são poucos estudos descritos na literatura.

Com relação à epidemiologia da SGB no Brasil, a predominância dos casos observados no Brasil, ocorreu nos estados de Minas Gerais, São Paulo, Rio de Janeiro e Espírito Santo no ano de 2018. Anualmente, considerando o período de 2001 a 2018, as maiores taxas apresentadas ocorreram entre os anos de 2015 e 2018, com maior intensidade em 2015 e 2016 . Neste último, o valor pode ser associado com o aumento da infecção em alguns estados, como Pernambuco e Bahia, pelo Zika vírus, um dos agentes virais que podem desencadear a SGB (Nóbrega et al.; 2018; OMS; 2016).

\section{Metodologia}

Esta revisão tem protocolo de estudo registrado no Open Science (https://osf.io/qe625). Os critérios utilizados para a elaboração da revisão sistemática foram baseados na metodologia PRISMA (Principais Itens para Relatar Revisões sistemáticas 
e Meta-Análises) (Galvão et al; 2015). Para os critérios de inclusão, utilizou-se artigos capazes de descrever o mecanismo da SGB secundária ao coronavírus em adultos. Não houve restrições quanto a linguagem ou data de publicação. Entretanto, não foram aceitas revisões sistemáticas, revisões narrativas, revisões de literatura ou metanálises. Também foram excluídos textos de caráter pediátrico, hebiátriaco, obstétrico e geriátrico. Após o período de coleta, as publicações foram inseridas no Mendeley Desktop em que dois grupos de avaliadores independentes realizaram a seleção dos estudos em duas etapas: a triagem e a leitura completa. A primeira fase ocorreu por meio da leitura de título e resumo, com base nos critérios de inclusão e exclusão citados na metodologia, os artigos eram aprovados na triagem. No segundo momento da pesquisa, os artigos aprovados na triagem por ambos os grupos foram lidos completamente e, somente então, eleitos aqueles que oferecem íntima relação ao tema. Os dados extraídos dos artigos foram: o país de realização do estudo ou do primeiro autor, desenho dos estudos, manifestações clínicas comuns à COVID-19, manifestações neurológicas relacionadas à infecção pós-COVID-19. Os dados foram, então, sintetizados e inseridos de forma manual em uma tabela no programa Microsoft Excel@ versão 2016. Após inserção dos dados, ocorreu análise minuciosa das informações, assim como avaliação dos critérios de inclusão e exclusão presentes. A Figura 1, a seguir, ilustra o processo de determinação dos artigos e seus resultados pela coleta de dados.

Figura 1: Fluxograma do processo de seleção de bases de dados.

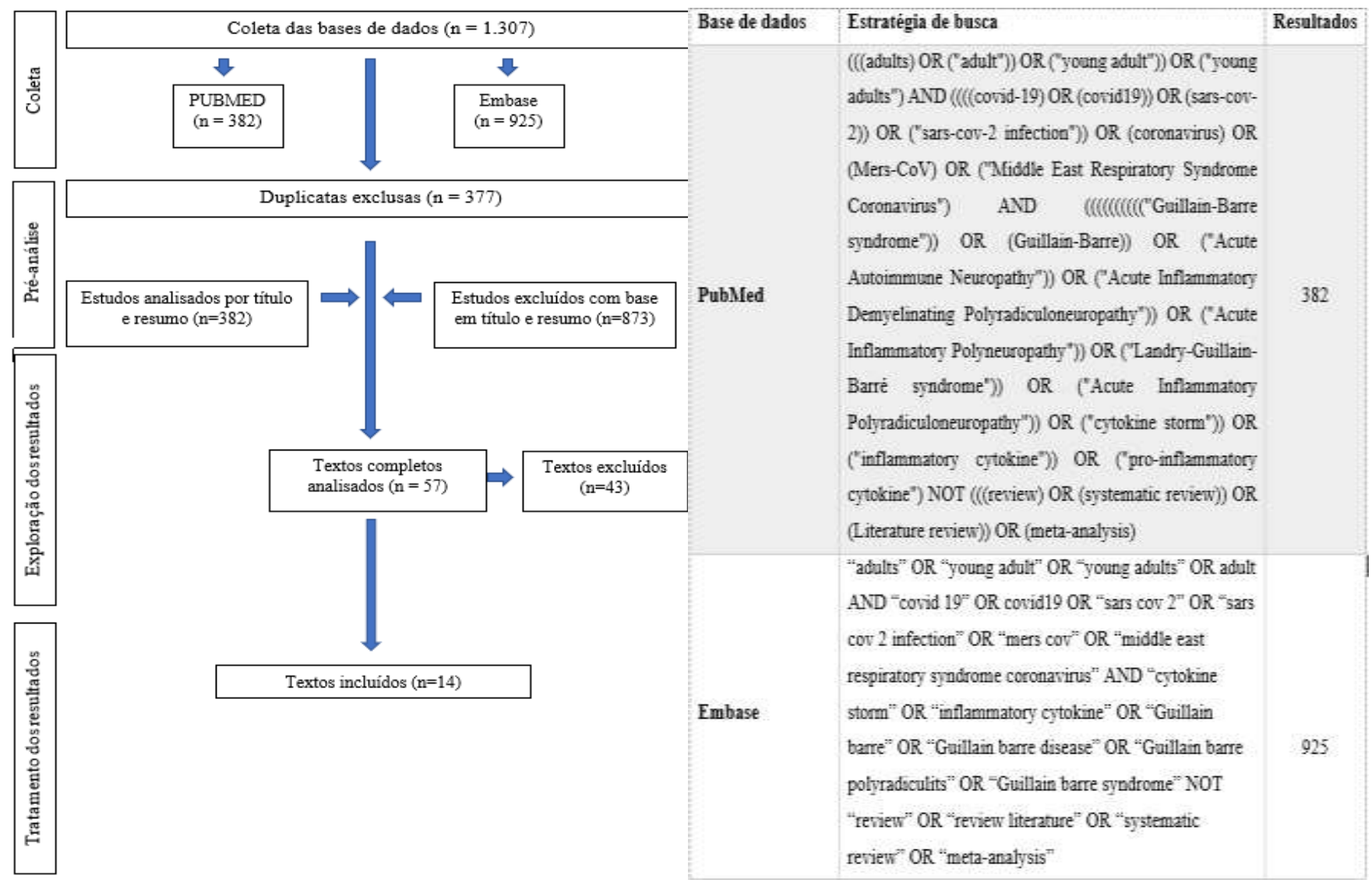

Fonte: Autores (2021).

\section{Resultados}

O resultado total da coleta foi de 1307 artigos, dos quais 377 eram duplicatas. Finalizada a triagem, 57 publicações foram aprovadas pela triagem, no entanto somente 11 foram eleitos para compor os resultados da pesquisa durante a leitura 
completa. Dentre os artigos eleitos, foram incluídos relatos de caso (9) e estudo coorte (2). Os estudos foram realizados nos Estados Unidos (2), Espanha (2), Reino Unido (1), Itália (1), França (1), Irã (1), Holanda (1), China (1), Suíça (1).

Dentre os artigos selecionados, foram utilizados 9 relatos de caso para realizar comparação do manejo dos casos suspeitos de SGB pós-COVID-19. Realizou-se a coleta de informações de 9 pacientes dos artigos utilizados, em que os dados constatados principais contidos nos relatos foram: escala Medical Research Council (MRC), Reverse Transcription-Polymerase Chain Reaction (RT-PCR) positivo para SARS-CoV-2 e as queixas neurológicas principais. Após análise dos resultados, estes foram inseridos na Tabela 1. Dentre os pacientes, 8 apresentaram RT-PCR positivo e 1 apresentou PCR nas amostras fecais positivas. Um total de $88,89 \%$ dos pacientes apresentou sintomas clássicos do Sars-CoV-2, tais como, febre, cefaleia, anosmia, fadiga e tosse. Os sintomas neurológicos deste grupo foram manifestados de 7 a 10 dias, sendo o tempo mínimo de 5 dias e o máximo de 22 dias. Parestesia e fraqueza muscular foram observadas na maioria dos resultados. As queixas neurológicas são restritas aos membros inferiores e superiores em 10 pacientes, sendo que um paciente apenas queixou-se de paralisia bilateral do nervo facial, com reflexo de piscar irresponsivo. Neste último caso, foi constatado que a apresentação clínica foi resultado de uma variação da SGB. A escala MRC foi avaliada em todos os pacientes, em que 77,78\% (7) apresentaram MRC alterada, cujos valores variaram de 4/5 ao 2/5 em membros superiores e inferiores. Os demais pacientes (1) não foram avaliados com relação à escala MRC.

Tabela 1: Resultados dos manejos clínicos presentes nos relatos de casos.

\begin{tabular}{|l|l|l|}
\hline \multicolumn{1}{|c|}{ MRC* } & RT-PCR & \multicolumn{1}{c|}{ Queixa neurológica principal } \\
\hline $\begin{array}{l}\text { 2/5 nas pernas; 2/5 nos braços; 3/5 nos antebraços e 4/5 } \\
\text { nas mãos }\end{array}$ & Positivo & Parestesia nos pés e mãos \\
\hline 1/5 membros inferiores; 2/5 membros superiores & Positivo & Fraqueza assimétrica \\
\hline Não informado/avaliado & Positivo & $\begin{array}{l}\text { Paralisia bilateral do nervo facial; reflexo de piscar } \\
\text { irresponsivo }\end{array}$ \\
\hline $\begin{array}{l}\text { 2/5 em extremidades dos membros inferiores e 3/5 em } \\
\text { extremidades dos membros superiores }\end{array}$ & Positivo & Dor lombossacral e fraqueza nas pernas e pés \\
\hline 5/5 nos braços e 4/5 nas pernas & Positivo & Fraqueza muscular ascendente \\
\hline 2/5 em flexão cervical; 4/5 tetraparesia & Positivo & Diplegia facial bilateral \\
\hline Não informado/avaliado & - & $\begin{array}{l}\text { Diplegia facial, fraqueza simétrica nos membros } \\
\text { inferiores e propriocepção prejudicada nas pernas }\end{array}$ \\
\hline 2/5 nos membros inferiores; 3/5 nos membros superiores & Positivo & Fraqueza progressiva simétrica ascendente \\
\hline 4/5 em mão esquerda & Positivo & Parestesia e fraqueza manual \\
\hline
\end{tabular}

*Foram utilizados estudos 1-9 para composição da tabela. O RT-PCR não informado é referente ao PCR de amostra fecal. Fonte: Autores (2021).

\section{Discussão}

O SARS-CoV-2 é um dos sete tipos de coronavírus já identificados em humanos. Durante a infecção, percebe-se uma relação da patogênese da doença com o sistema renina angiotensina. O vírus, ao se aderir no epitélio alveolar, apresenta tropismo com a enzima conversora de angiotensina 2 (ECA-2) que atua como receptor tecidual intermediando as primeiras etapas da infecção (Salle; 2021). A ligação da proteína S (do inglês: Spike) viral com o ECA-2 não somente contribui para a instalação viral e sintomas respiratórios como também a presença destes receptores em outros sistemas do organismo juntamente com uma hiperativação imunológica resulta em uma ampla sintomatologia que varia desde o acometimento respiratório (tosse, dispneia, síndrome do desconforto respiratório agudo e pneumonia), até o envolvimento sistêmico extrapulmonar como em disfunções 
cardíacas, renais, hepáticas, urológicas e neurológicas.

Diante disso, o acometimento do sistema nervoso central e periférico pelo SARS-CoV-2 vem sendo amplamente relatado na literatura, devido às diversas formas e relatos de manifestações neurológicas. Os coronavírus apresentam um elevado neurotropismo, em que a entrada do SARS-CoV-2 no sistema nervoso relaciona-se com mesmos os trajetos apresentados por outros coronavírus e diversos vírus já conhecidos. Os possíveis mecanismos de disseminação para o sistema nervoso incluem o envolvimento de nervos olfatórios sensitivos no epitélio nasal, transporte neuronal retrógrado dos aferentes do nervo vago, nervos entéricos periféricos, nervo trigêmeo relacionado com células nociceptivas da cavidade nasal e fibras sensoriais conjuntivas oculares e via hematogênica através da destruição da barreira hematoencefálica (BHE) (Keyhanian et al.; 2021). Os neurônios e as células da glia também expressam receptores ECA-2 o que resulta muito frequentemente em manifestações neurológicas como fadiga, mialgia, cefaleia, tontura, ageusia e anosmia (Singh et al.; 2021). Após os surtos de SARS-CoV e MERS-CoV, diversos estudos elucidaram a capacidade dos variados coronavírus de indução de quadros autoimunes (Salle; 2021).

Recentemente, foi relatado o desenvolvimento de doenças autoimunes desencadeadas após a infecção do SARS-CoV2, dentre elas a SGB, uma polirradiculoneuropatia imune aguda caracterizada pelo acometimento de nervos motores, sensoriais e autonômicos. Mais comumente, pacientes que apresentaram SGB associado a infecção do novo coronavírus se manifestaram com uma rápida e progressiva flacidez, fraqueza e parestesia dos membros distalmente (Keyhanian et al.; 2021). A síndrome pode ser classificada clinicamente ou por meio do diagnóstico eletroneuromiográfico. Quanto às formas clínicas, a SGB pode assumir diferentes subtipos clínicos como a Síndrome de Miller Fisher, paralisia bilateral com parestesias, paraparesia, variantes faríngea-cervical-braquial, polineurite craniana e encefalite do tronco cerebral de Bickerstaff (Andalib et al.; 2021).

Já uma abordagem eletrofisiológica, estudos de condução nervosa por meio do diagnóstico eletroneuromiográfico podem avaliar o envolvimento desmielinizante e axonal classificando a SGB em polineuropatia desmielinizante inflamatória aguda (PDIA), neuropatia axonal sensitivo-motora aguda (NASMA) e Neuropatia axonal motora aguda (NAMA) (Soltani et. al; 2019). Alguns autores afirmam que os subtipos axonais (NASMA e NAMA) são os fenótipos mais comumente apresentados pelos pacientes de COVID-19 associado a SGB, embora haja discordâncias na literatura que indicam o predomínio do subtipo PDIA (Andalib et al.; 2021; Sriwastava et al.; 2021). Apesar de rara, a síndrome de Miller Fisher é a variante clínica mais comum da SGB caracterizada pela tríade de ataxia, arreflexia e oftalmoplegia e sua associação com a infeção com o novo coronavírus é elucidada em diversos estudos (Andalib et al.; 2021; Freire et al.; 2021; Keyhanian et al.; 2021).

Assim como os mecanismos de disseminação para o sistema nervoso, a fisiopatologia das manifestações da SGB associada ao SARS-Cov-2 ainda não são totalmente conhecidas. Freire et al (2021) cita três possíveis mecanismos patogênicos responsáveis pelo dano neurológico da COVID-19: dano direto, resposta inflamatória desregulada e lesão mediada por anticorpos. O período de latência para o desenvolvimento da SGB é variado e pode se relacionar com os mecanismos de patogênese. $O$ tempo médio de latência é de 11 dias, apesar da existência de períodos maiores que um mês (Freire et al.; 2021). Tal longo período de latência pode estar relacionado com a teoria de lesão tardia, no qual, assim como no Zika vírus associado à SGB, é resultado da ativação do sistema imune adaptativo, cujos autoanticorpos danificam os nervos periféricos por meio de um mimetismo molecular caracterizado por uma reatividade cruzada entre epítopos virais e antígenos dos nervos (Freire et al.; 2021; Mohammad et al.; 2020; Sriwastava et al.; 2021).

Entretanto, pelo fato da maioria dos casos de SGB associado à infecção do novo coronavírus não estar presentes autoanticorpos, e a maior parte dos pacientes apresentarem um curto período de latência com a elevação de marcadores inflamatórios séricos, acredita-se que a resposta imune celular e inata sobrepõe aos fatores humorais e de mimetismo antigênicos (Freire et al.; 2021). Dentre os mecanismos que sustentam tais achados, cabe citar o efeito citopático presente no dano direto durante a invasão viral no sistema nervoso, seja pela destruição da BHE ou pelo transporte axonal retrógrado de nervos cranianos ou enterais (Freire et al.; 2021; Keyhanian et al.; 2021; Sriwastava et al.; 2021). 
Alguns autores demonstraram relatos de pacientes que apresentaram período de latência para o desenvolvimento da SGB de 0 dias e outros relataram a manifestação da síndrome em pacientes sem sintomas de COVID-19 (assintomáticos) (Sriwastava et al.; 2021). A resposta inflamatória desregulada durante a neuroinflamação ocorre normalmente na segunda semana, período que coincide com a média do período de latência da SGB, e é caracterizada pelo desvio pró-inflamatório, de predomínio do padrão Th1 (do inglês: T- helper 1), com elevada produção de citocinas, como interleucina 2 (IL-2), IL-6, IL-7, IL-10, interferon- $\gamma$ (IFN- $\gamma$ ), fator de necrose tumoral- alfa (TNF- $\alpha$ ), dentre outras, que contribuem para a chamada "tempestade de citocinas", caracterizada pela ativação exacerbada da resposta imunidade inata e celular, representada pela infiltração de monócitos, macrófagos e linfócitos T nas células neurais (Freire et al.; 2021; Keyhanian et al.; 2021).

O dano direto durante a neuroinflamação pode ser sustentada ainda pelo aumento excessivo de IL-6 e TNF- $\alpha$, que contribui para a destruição da BHE, o qual pode estar associada a sintomas de encefalite e SGB (Keyhanian et al.; 2021). Freire et al. (2021) relaciona ainda o subtipo PDIA com o predomínio da resposta imune celular na imunopatologia da SGB, enquanto os padrões NASMA e NAMA apresentam uma elevada associação com a presença de anticorpos IgG para o gangliosídeo GM1 (anti-GM1), indicando assim um predomínio de lesão mediada por anticorpos nesses fenótipos. A Figura 2 ilustra os possíveis processos imunopatológicos do SARS-CoV-2 no Sistema Nervoso.

Sriwastava et al (2021) elucida ainda que SGB quando associada à COVID-19 requer uma maior atenção por parte dos profissionais da saúde não somente por estar frequentemente associada a necessidade de intubação e ventilação mecânica mesmo na ausência de achados neuromusculares como parestesia e ptose, mas também por ser uma síndrome de difícil diagnóstico. O diagnóstico da SGB é dificultado por sintomas comuns da infecção por SARS-CoV-2 como dispneia e fadiga, o que atrasa o diagnóstico clínico e tratamento da síndrome neurológica, relacionado a um pior prognóstico. Na presença da polirradiculoneuropatia, os pacientes geralmente respondem bem à terapia por imunoglobulina humana intravenosa (IVIG) e plasmaferese. (Singh et al.; 2021; Sriwastava et al.; 2021). Alguns possíveis mecanismos podem justificar a eficácia do tratamento com imunoglobulina intravenosa, dentre eles a supressão da produção de citocinas pró-inflamatórias, como IL-2 e IFN- $\gamma$, neutralização dos anticorpos anti-GM1, supressão do sistema do complemento, bloqueio de receptores Fc (do inglês: fragment crystallization) de macrófagos e estímulo de remielinização. (Ebrahim et. al; 2019)

Outros agentes virais da família coronavírus são capazes de desenvolver SGB com mecanismos semelhantes aos do SARS-CoV-2, o que favorece a compreensão da imunopatogenia. A síndrome respiratória aguda grave (SARS), por exemplo, é uma doença que surgiu em 2003 na Ásia e se manifestava principalmente como uma infecção respiratória aguda. Estudos demonstram que essa síndrome causada pelo SARS-CoV é capaz de invadir o sistema nervoso central e causar déficits neurológicos, dentre eles a SGB.

O primeiro fator que elucida essa invasão central é a presença de edema cerebral e vasodilatação meníngea, em estudos realizados em autópsia de cadáveres. Essas autópsias ainda evidenciaram que linfócitos e monócitos, ao infiltrarem na parede de vasos cerebrais, podem acentuar o processo de degeneração e desmielinização neural, associados ao subtipo de polineuropatia desmielinizante inflamatória aguda (PDIA).

Em segundo lugar, foram encontradas sequências genômicas de SARS-CoV no líquor e ao longo do hipotálamo e córtex de pacientes infectados. Em terceiro lugar é a presença da ECA-2 em células da glia humana que, assim como para o SARSCoV-2, age como receptor para o SARS-CoV. A ligação do vírus por meio de sua proteína $\mathrm{S}$ à ECA-2 associada à sua clivagem proteolítica facilita a entrada na célula e posterior invasão do sistema nervoso. Outro fator que pode estar interligado é a resposta inflamatória exacerbada frente ao estímulo da infecção viral. A invasão do vírus em macrófagos, monócitos e células dendríticas do hospedeiro pode provocar uma "tempestade" de citocinas pró-inflamatórias como IL-6 e IFN- $\gamma$, deixando-o mais susceptível à complicações neurológicas. Por fim, testes de imunofluorescência em pacientes indicaram a presença de autoanticorpos que podem estar relacionados ao desencadeamento da SGB (Mohammad et al.; 2020, Nampoothiri et al.;2020). 
O MERS-CoV, causador da síndrome respiratória do Oriente Médio (MERS) é um outro tipo de infecção respiratória causada por um coronavírus. O primeiro caso reportado foi na Arábia Saudita em 2012 (Mohammad et al.; 2020). Tipicamente, os pacientes manifestam febre, mialgia, tosse e dispneia que frequentemente evoluem para pneumonia (Kim et al; 2017). Cerca de $20 \%$ dos pacientes contaminados cursam com complicações neurológicas, sendo a SGB a mais prevalente, e o período médio de latência para o aparecimento desses sintomas é de 2 a 3 semanas. O mecanismo de acometimento neural é muito semelhante ao dos pacientes infectados pelo SARS-CoV e pelo SARS-CoV-2, com um aumento na circulação de citocinas inflamatórias e produção de anticorpos autorreativos (Mohammad et al.; 2020). Esses fatores garantem a característica neurotrófica e neuroinvasiva desses vírus que cursam com a SGB. Uma vez instalada, essa síndrome é comumente acompanhada de disautonomia e paralisia dos nervos cranianos, que contribui para a diferenciação do diagnóstico com outros tipos de acometimentos neurológicos (Kim et al; 2017).

Figura 2: Esquema imunopatológico de infecção do SARS-CoV-2 no SN.

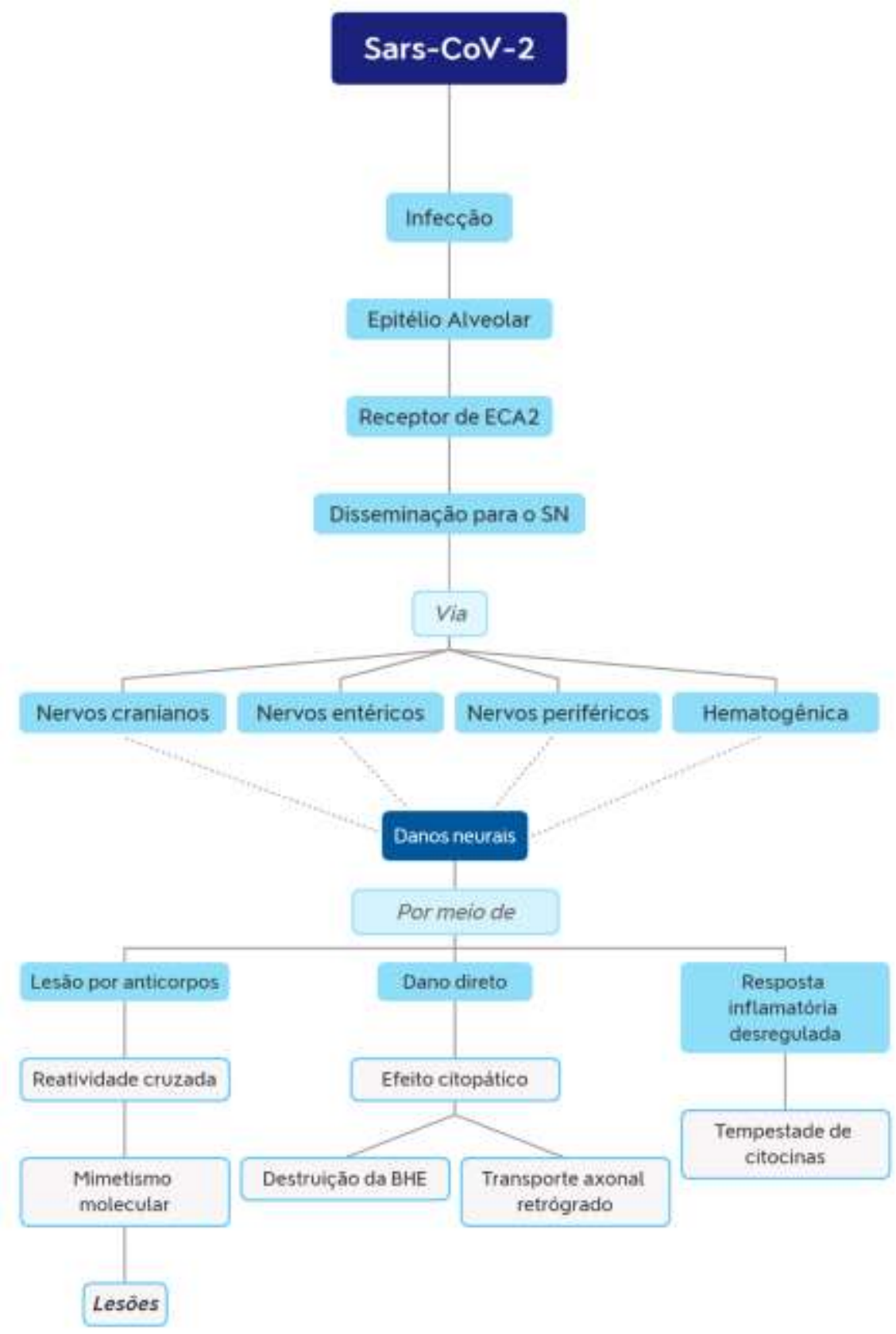

Fonte: Autores (2021). 


\section{Conclusão}

De acordo com os resultados, a maioria dos estudos analisados aponta uma relação imunológica e inflamatória da COVID-19 com o desencadeamento da SGB. Além disso, foi mostrado também que outros coronavírus, como o SARS-CoV, parece estar associado ao desenvolvimento da síndrome. O mecanismo por trás da SGB está ligado a uma intensa produção de citocinas pró-inflamatórias que ativam células da resposta imune inata e celular e, geram lesões nas estruturas neurais, podendo se manifestar por meio de sintomas locais ou culminar com polineuropatias, como é o caso da SGB. No entanto, a literatura atual que pontua as possíveis relações é escassa, sendo necessário analisar a variabilidade de mecanismos relacionados com a imunopatologia do Sars-CoV-2 para poder afirmar com clareza se o vírus realmente é capaz de desencadear a SGB. Para isso, é preciso realizar estudos direcionados em grupos populacionais semelhantes, sem patologias anteriores, submetidos aos mesmos exames para testagem de COVID-19 e submetidos às mesmas medidas terapêuticas.

Em função do tema ser ainda pouco abordado na literatura, concomitante ao escasso conhecimento sobre este entre os profissionais da área saúde, o presente trabalho possui o papel de atualizar estes profissionais, incrementar as bases de dados e fornecer melhores parâmetros para estudos mais complexos sobre o tema. Para trabalhos futuros, recomenda-se uma avaliação com um maior número de pacientes que apresentaram complicações neurológicas de SGB após a infecção por SARS-CoV-2, o que poderia ser realizado por meio de pesquisas de campo. A partir do contato direto com pacientes seria possível a realização de exames com posterior análise mais detalhada dos resultados, e assim melhor compreensão do funcionamento da imunopatologia do SARS-CoV-2 e demais complicações, além da SGB, que podem estar associada e não relatadas ainda.

\section{Conflito de interesses}

Os autores não declararam conflito de interesses.

\section{Referências}

Ameer, N., Shekhda, K. M., \& Cheesman, A. (2020). Guillain-Barré syndrome presenting with COVID-19 infection. BMJ Case Reports CP, 13 (9), e236978. https://doi.org/10.1136/bcr-2020-236978

Andalib, S., Biller, J., Di Napoli, M., Moghimi, N., McCullough, L. D., Rubinos, C. A., O’Hana Nobleza, C., Azarpazhooh, M. R., Catanese, L., Elicer, I., Jafari, M., Liberati, F., Camejo, C., Torbey, M., \& Divani, A. A. (2021). Peripheral nervous system manifestations associated with covid-19. Current Neurology and Neuroscience Reports, 21(3), 9. https://doi.org/10.1007/s11910-021-01102-5

Benvenuto, A., Carella, A. M., Conte, M., Florio, C., De Luca, P., Modola, G., Damone, F. P., Marinelli, T., Nargiso, M., Ciavarrella, G., \& Di Pumpo, M. (2020). Atypical clinical presentation of COVID-19: A case of Guillain-Barrè Syndrome related to SARS-CoV-2 infection. Italian Journal of Medicine, 119119.

Boostani, R., Talab, F. R., Meibodi, N. T., \& Zemorshidi, F. (2021). COVID-19 associated with sensorimotor polyradiculoneuropathy and skin lesions: A case report. Journal of Neuroimmunology, 350, 577434. https://doi.org/10.1016/j.jneuroim.2020.577434

Bueso, T., Montalvan, V., Lee, J., Gomez, J., Ball, S., Shoustari, A., Julayanont, P., \& Jumper, C. (2021). Guillain-barre syndrome and covid-19: A case report. Clinical Neurology and Neurosurgery, 200, 106413. https://doi.org/10.1016/j.clineuro.2020.106413

Camdessanche, J.-P., Morel, J., Pozzetto, B., Paul, S., Tholance, Y., \& Botelho-Nevers, E. (2020). COVID-19 may induce Guillain-Barré syndrome. Revue Neurologique, 176(6), 516-518. https://doi.org/10.1016/j.neurol.2020.04.003

Créange, A. (2016). Guillain-Barré syndrome: 100 years on. Revue Neurologique, 172(12), 770-774. https://doi.org/10.1016/j.neurol.2016.10.011

Ebrahim Soltani, Z., Rahmani, F., \& Rezaei, N. (2019). Autoimmunity and cytokines in Guillain-Barré syndrome revisited: Review of pathomechanisms with an eye on therapeutic options. European Cytokine Network, 30(1), 1-14. https://doi.org/10.1684/ecn.2019.0424

Freire, M., Andrade, A., Sopeña, B., Lopez-Rodriguez, M., Varela, P., Cacabelos, P., Esteban, H., \& González-Quintela, A. (2021). Guillain Barré syndrome associated with COVID-19- lessons learned about its pathogenesis during the first year of the pandemic, a systematic review. Autoimmunity Reviews, 20(8), 102875. https://doi.org/10.1016/j.autrev.2021.102875

Gale, A., Sabaretnam, S., \& Lewinsohn, A. (2020). Guillain-Barré syndrome and COVID-19: Association or coincidence. BMJ Case Reports CP, 13(11), e239241. https://doi.org/10.1136/bcr-2020-239241

Galvão, T. F., Pansani, T. de S. A., \& Harrad, D. (2015). Principais itens para relatar Revisões sistemáticas e Meta-análises: A recomendação PRISMA. Epidemiologia e Serviços de Saúde, 24(2), 335-342. https://doi.org/10.5123/S1679-49742015000200017 
Juliao Caamaño, D. S., \& Alonso Beato, R. (2020). Facial diplegia, a possible atypical variant of Guillain-Barré Syndrome as a rare neurological complication of SARS-CoV-2. Journal of Clinical Neuroscience, 77, 230-232. https://doi.org/10.1016/j.jocn.2020.05.016

Keyhanian, K., Umeton, R. P., Mohit, B., Davoudi, V., Hajighasemi, F., \& Ghasemi, M. (2021). SARS-CoV-2 and nervous system: From pathogenesis to clinical manifestation. Journal of Neuroimmunology, 350, 577436. https://doi.org/10.1016/j.jneuroim.2020.577436

Kilinc, D., Pasch, S., Doets, A. Y., Jacobs, B. C., Vliet, J., \& Garssen, M. P. J. (2020). Guillain-Barré syndrome after SARS-CoV-2 infection. European Journal of Neurology, 27(9), 1757-1758. https://doi.org/10.1111/ene.14398

Kim, J.-E., Heo, J.-H., Kim, H., Song, S., Park, S.-S., Park, T.-H., Ahn, J.-Y., Kim, M.-K., \& Choi, J.-P. (2017). Neurological complications during treatment of middle east respiratory syndrome. Journal of Clinical Neurology, 13(3), 227. https://doi.org/10.3988/jcn.2017.13.3.227

Lascano, A. M., Epiney, J. -B., Coen, M., Serratrice, J., Bernard-Valnet, R., Lalive, P. H., Kuntzer, T., \& Hübers, A. (2020). SARS-CoV-2 and Guillain-Barré syndrome: AIDP variant with a favourable outcome. European Journal of Neurology, 27(9), 1751-1753. https://doi.org/10.1111/ene.14368

Leonhard, S. E., Bresani-Salvi, C. C., Lyra Batista, J. D., Cunha, S., Jacobs, B. C., Brito Ferreira, M. L., \& P. Militão de Albuquerque, M. de F. (2020). GuillainBarré syndrome related to Zika virus infection: A systematic review and meta-analysis of the clinical and electrophysiological phenotype. PLOS Neglected Tropical Diseases, 14(4), e0008264. https://doi.org/10.1371/journal.pntd.0008264

$\mathrm{Li}, \mathrm{Z}$. (2021). Bioinformatic analyses hinted at augmented T helper 17 cell differentiation and cytokine response as the central mechanism of COVID- 19associated Guillain- Barré syndrome. Cell prolifation. https://onlinelibrary.wiley.com/doi/epdf/10.1111/cpr.13024?src=getftr

Mohammadi, S., Moosaie, F., \& Aarabi, M. H. (2020). Understanding the immunologic characteristics of neurologic manifestations of sars-cov-2 and potential immunological mechanisms. Molecular Neurobiology, 57(12), 5263-5275. https://doi.org/10.1007/s12035-020-02094-y

Nampoothiri, S., Sauve, F., Ternier, G., Fernandois, D., Coelho, C., Imbernon, M., Deligia, E., Perbet, R., Florent, V., Baroncini, M., Pasquier, F., Trottein, F., Maurage, C.-A., Mattot, V., Giacobini, P., Rasika, S., \& Prevot, V. (2020). The hypothalamus as a hub for SARS-CoV-2 brain infection and pathogenesis [Preprint]. Neuroscience. https://doi.org/10.1101/2020.06.08.139329

Nóbrega, M. E. B. da, Araújo, E. L. de L., Wada, M. Y., Leite, P. L. e, Dimech, G. S., \& Pércio, J. (2018). Surto de síndrome de Guillain-Barré possivelmente relacionado à infecção prévia pelo vírus Zika, Região Metropolitana do Recife, Pernambuco, Brasil, 2015. Epidemiologia e Serviços de Saúde, 27(2), https://doi.org/10.5123/S1679-49742018000200016

Petersen, L. R., Jamieson, D. J., Powers, A. M., \& Honein, M. A. (2016). Zika virus. New England Journal of Medicine, 374(16), 1552-1563. https://doi.org/10.1056/NEJMra1602113

Salle, V. (2021). Coronavirus-induced autoimmunity. Clinical Immunology, 226, 108694. https://doi.org/10.1016/j.clim.2021.108694

Sancho-Saldaña, A., Lambea-Gil, Á., Liesa, J. L. C., Caballo, M. R. B., Garay, M. H., Celada, D. R., \& Serrano-Ponz, M. (2020). Guillain-Barré syndrome associated with leptomeningeal enhancement following SARS-CoV-2 infection. Clinical Medicine, 20(4), e93-e94. https://doi.org/10.7861/clinmed.2020-0213

Singh, R., Shiza, S. T., Saadat, R., Dawe, M., \& Rehman, U. (2021). Association of guillain-barre syndrome with covid-19: A case report and literature review. Cureus. https://doi.org/10.7759/cureus.13828

Sriwastava, S., Kataria, S., Tandon, M., Patel, J., Patel, R., Jowkar, A., Daimee, M., Bernitsas, E., Jaiswal, P., \& Lisak, R. P. (2021). Guillain Barré Syndrome and its variants as a manifestation of COVID-19: A systematic review of case reports and case series. Journal of the Neurological Sciences, $420,117263$. https://doi.org/10.1016/j.jns.2020.117263

Wakerley, B. R., Uncini, A., Yuki, N., GBS Classification Group, \& GBS Classification Group. (2014). Guillain-Barré and Miller Fisher syndromes-New diagnostic classification. Nature Reviews. Neurology, 10(9), 537-544. https://doi.org/10.1038/nrneurol.2014.138

Willison, H. J., Jacobs, B. C., \& van Doorn, P. A. (2016). Guillain-Barré syndrome. The Lancet, 388(10045), 717-727. https://doi.org/10.1016/S01406736(16)00339-1

Yachou, Y., El Idrissi, A., Belapasov, V., \& Ait Benali, S. (2020). Neuroinvasion, neurotropic, and neuroinflammatory events of SARS-CoV-2: Understanding the neurological manifestations in COVID-19 patients. Neurological Sciences, 41(10), 2657-2669. https://doi.org/10.1007/s10072-020-04575-3 